\section{Fasting and Post Prandial Monitoring of Dipeptidyl Peptidase-Iv (Dpp-Iv) - A Biomarker To Assess Incretin Response In Type-2 Diabetes}

\author{
Venkatesham Allenki ${ }^{1}$, Rama Krishna Devarakonda ${ }^{1}$, Rama Narsimha \\ Reddy Anreddy ${ }^{1}$, Narayana Pantam ${ }^{2}$, Narsimha Reddy Yellu ${ }^{1^{*}}$. \\ University College of Pharmaceutical Sciences ${ }^{2}$, Kakatiya University, \\ Warangal - 506 009, Andhra Pradesh, INDIA. \\ Department of General Medicine 1 , Mahatma Gandhi Memorial Hospital, \\ Warangal - 506 002, Andhra Pradesh, INDIA
}

\author{
${ }^{*}$ Corresponding Author \\ Dr. Narsimha Reddy Yellu \\ Associate Professor \\ Pharmacology \& Clinical Pharmacy Division \\ University College of Pharmaceutical \\ Sciences, Kakatiya University, \\ Contact No.: +91-870-2461433. \\ E-mail: yellu_nr@yahoo.com
}

Received-22 May, 2009

Accepted for Publication-15 December, 2009

\begin{abstract}
Dipeptidyl peptidase-IV (DPP-IV) could serve as a potential biomarker in monitoring the disease progression and improvement on treatment. To investigate fasting \& post prandial response of DPP-IV enzyme as indirect marker of incretin response failure after chronic treatment with metformin in type 2 diabetes. The study included twelve nondiabetic subjects, ten patients with glycosylated hemoglobin values (6-8 \%) and fifteen patients with glycosylated hemoglobin greater than $8 \%$ of type-2 diabetes patients of either sex with metformin treatment above 3 years were recruited. Fasting and post prandial DPP-IV levels were calculated. HbA1c was used to assess diabetes status. DPP-IV activity (fasting) in type 2 diabetic subjects with $\mathrm{HbA} 1 \mathrm{c}>8 \%$ was significantly higher DPP-IV $(44.67 \pm 2.19 \mathrm{U} / \mathrm{l})$ than in non diabetic subjects $(24.39 \pm 3.97 \mathrm{U} / \mathrm{l})$. A significant correlation between DPP-IV (fasting / post prandial) and HbA1c $(r=0.821 \& r=0.732$, $\mathrm{P}<0.01)$ was observed in both diabetic $(\mathrm{HbA1c} 6-8, \mathrm{HbA1c}<8)$ patients. Hyperglycemia induces significant increase in serum DPP-IV activity in fasting condition and might contribute to the reduction in active glucagon like peptide-1(GLP-1) in type 2 diabetic subjects. In normal subjects during post prandial condition, there is sudden increase followed by decrease of GLP-1 due to cleavage of GLP-1 to as substrate of DPP-IV is seen as upsurge of DPP-IV. This response was lacking in diabetic patients with high $\mathrm{HbA1c}$ indicates indirectly metformin failure to secrete GLP-1. High fasting level and decreased post prandial of DPP-IV may indicate drug failure in type-2 diabetes mellitus.
\end{abstract}

Key words: Type 2 diabetes, metformin, DPP-IV, HbA1c and GLP-1.

\title{
INTRODUCTION
}

Type 2 diabetes mellitus is characterized by the postprandial and fasting hyperglycemia, which is due to a failure of pancreatic beta cells to secrete adequate insulin to compensate for insulin resistance in peripheral tissues (Weyer $\mathrm{C}$ et al. 1999). Dipeptidyl peptidase IV (CD26; E.C. 3.4.14.5) is a $110-\mathrm{kDa}$ plasma membrane glycoprotein ectopeptidase that belongs to the prolyl oligopeptidase family (Lambeir A-M et al. 2003). In mammals, DPP-IV was widely expressed on the surface of endothelial and epithelial cells (Low SH et al. 1991) and highest levels in humans have been reported to occur in the intestine, bone marrow and kidney (Vanhoof $G$ et al. 1992). Glucagon like peptide-1(GLP-1) is a gastrointestinal hormone produced in enteroendocrine cells in the distal small bowel and colon. Plasma levels of GLP-1 also rise rapidly within minutes of food intake. Bioactive GLP-1 is generated from GLP-1(1-37) and exists as two equipotent circulating molecular forms, GLP-1(7-37) and GLP-1(7-36) amide. GLP-1(7-36) amide represents the majority of circulating active GLP-1 in human plasma (Orskov C et al. 1994). Metformin stimulate secretion of GLP-1 from gut in response to food, in addition to decreased hepatic glucose output due to decreased hepatic gluconeogenesis (Christiansen MP and Hellerstein MK. 1998). Both forms of GLP-1 are rapidly degraded by DPP-IV to GLP-1(9-36) amide or GLP-1(9-37) following release from gut $L$ cells. GLP-1 directly enhances glucose-dependent insulin secretion via an increase in $\beta$-cell cAMP (Drucker DJ et al. 1987) through both protein kinase A-dependent and independent mechanisms, with activation of signalling through small G-proteins contributing to control of insulin 
exocytosis (Kashima $Y$ et al. 2001). GLP-1 receptor (GLP-1R) activation also promotes calcium mobilization (Holz GG et al.1995) and closure of the ATP-sensitive KATP channel (Light PE et al. 2002). The insulinotropic activity of GLP-1 is mediated through GLP-1 receptors on pancreatic beta cells. GLP-1 also increases insulin gene promoter activity and insulin biosynthesis in cell lines (Wang Y et al. 1995). GLP-1 also lowers blood glucose via inhibition of gastric emptying (Willms B et al. 1996). In view of these findings, hyperglycemia might be attributed to the high levels of circulating DPP-IV, which leads to impairment of GLP-1 secretion. In the present study we have evaluated the correlations between DPP-IV levels (fasting and post prandial) and HbA1using anthropometric and biochemical variables in subjects with different degrees of glucose tolerance.

\section{MATERIALS AND METHODS}

The study included twelve nondiabetic subjects, ten mild diabetic patients with glycosylated hemoglobin values (6-8\%) and fifteen diabetic patients with glycosylated hemoglobin value greater than $8 \%$ of type-2 diabetes patients treated with metformin $(500 \mathrm{mg}, \mathrm{po})$ more than three years of either sex were recruited at the Department of General Medicine, Mahatma Gandhi Memorial Hospital, Warangal, Andhra Pradesh, India from January 2006 to September 2006. All subjects were attending general health check up at the out patient department (Thursday-Diabetic Care Programme) in MGM Hospital. Subjects were excluded if they had chronic gastrointestinal diseases associated with chronic pancreatitis, history of any malignant disease, history of alcohol abuse, kidney or liver failure and other diseases affecting carbohydrate metabolism. Fasting as well as post prandial blood samples were collected from all subjects. DPP-IV activity was measured by a colorimetric assay. Gly-Pro-4 p-nitroanilide, a chromogenic substrate of DPP-IV, is hydrolysed into the dipeptide Gly-Pro and the product 4-nitroaniline, the rate of appearance of which could be measured spectrophotometrically (Durinx $C$ et al. 2001) and HbA1c was estimated by ion exchange resin method (Trivelli LIA. 1971 and Bunn H. F. 1981). The study protocol was approved by institutional ethics committee (Kakatiya Medical College, Warangal). The study was conducted as per good clinical practice guidelines, in accordance with the Declaration of Helsinki.

\section{Statistical analysis}

The values expressed as mean \pm SD. Relationships between variables were determined by Pearson's correlation coefficient. All analyses were performed using Graph Pad Prism software package (Version 4.01, Graph Pad Software, Inc. USA) to find out the level of significance. $\mathrm{P}<0.05$ was considered as statistically significant.

\section{RESULTS}

Figure 1 shows serum DPP-IV levels in different groups (fasting / post prandial). DPP-IV activity (fasting) in type 2 diabetic subjects with $\mathrm{HbA1c}>8 \%$ was significantly higher DPP-IV (44.67 \pm $2.19 \mathrm{U} / \mathrm{l})$ than in non diabetic subjects $(24.39 \pm 3.97 \mathrm{U} / \mathrm{l})$.

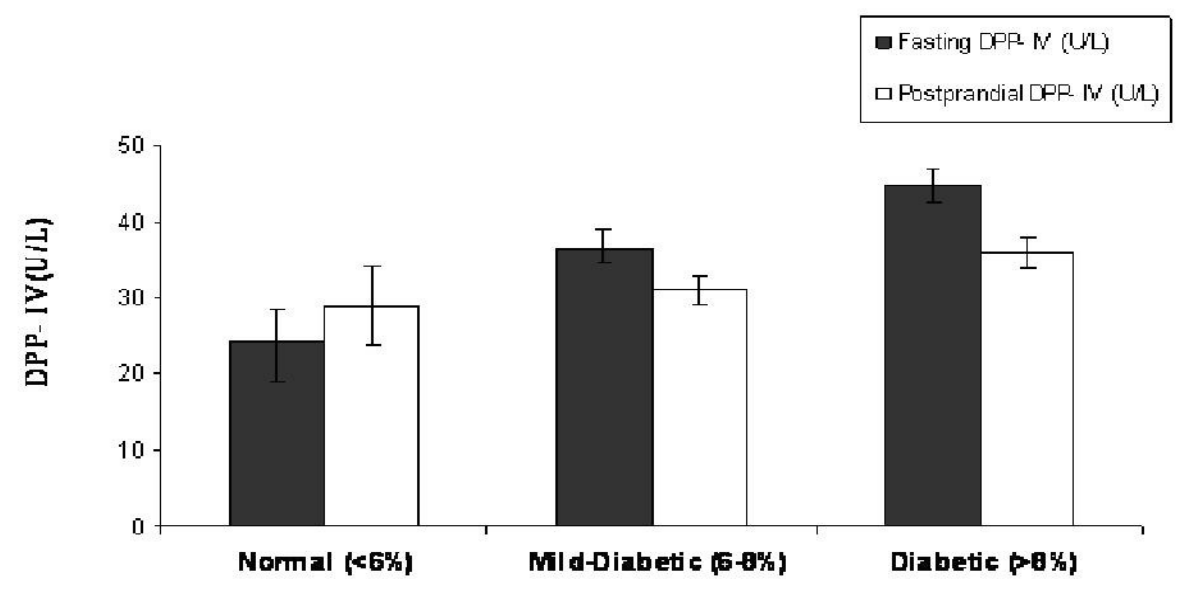

GROU PS 
Figure-1. Serum dipeptidyl peptidase IV (DPP-IV) levels in different groups of subjects. Values are expressed as mean \pm SD.

Table 1. Clinical characteristics of subjects participating in the study.

\begin{tabular}{lccc}
\hline PARAMETERS & $\begin{array}{c}\text { NON DIABETIC } \\
\text { (HbA1c }<6 \%)\end{array}$ & $\begin{array}{c}\text { MILD DIABETIC } \\
\text { (HbA1c 6-8\%) }\end{array}$ & $\begin{array}{c}\text { DIABETIC } \\
\text { (HbA1c >8\%) }\end{array}$ \\
\hline Age (years) & $47.08 \pm 2.61$ & $56.0 \pm 1.60$ & $52.27 \pm 10$ \\
Sex (men / women) & $12(6 \mathrm{M} / 6 \mathrm{~F})$ & $10(5 \mathrm{M} / 5 \mathrm{~F})$ & $15(8 \mathrm{M} / 7 \mathrm{~F}$ \\
BMI (kg/m $\left.{ }^{2}\right)$ & $22.29 \pm 1.92$ & $23.74 \pm 4.07$ & $23.31 \pm 4.06$ \\
Fasting DPP- IV (U/l) & $24.39 \pm 3.97$ & $36.52 \pm 2.50$ & $44.67 \pm 2.19$ \\
Postprandial DPP- IV (U/l) & $29.02 \pm 5.18$ & $31.06 \pm 1.80$ & $35.90 \pm 2.10$ \\
HbA ${ }_{1} \mathrm{C}(\%)$ & $5.37 \pm 0.50$ & $7.34 \pm 0.49$ & $11.06 \pm 2.17$ \\
$\begin{array}{l}\text { DPP-IV ratio } \\
\text { (Fasting/Post Prandial) }\end{array}$ & $0.85 \pm 0.16$ & $1.18 \pm 0.04$ & $1.25 \pm 0.27$ \\
\hline Values are expressed as mean \pm SD. & &
\end{tabular}

Table 1 represents the clinical characteristics of all the subjects. A significant correlation between DPP-IV (fasting / post prandial) and HbA1c $(r=0.821 \& r=0.732, P<0.01)$ was observed in both diabetic $(\mathrm{HbA} 1 \mathrm{c}$ 6-8 \& HbA1c < 8) patients. Table 2 represents correlations between DPP-IV (fasting / postprandial) and HbA1c. The ratio of fasting and postprandial DPP-IV on normal subjects and diabetic subjects was studied. In normal subjects, it is less than 1 but in diabetic subjects on metformin treated is reversed i.e greater than 1 .

Table 2. Univariate correlations with HbA1c of different subjects.

\begin{tabular}{|c|c|c|c|c|c|c|}
\hline \multirow[b]{3}{*}{ PARAMETERS } & \multicolumn{2}{|c|}{$\begin{array}{c}\text { NON DIABETIC } \\
(<6 \%)\end{array}$} & \multicolumn{2}{|c|}{$\begin{array}{c}\text { MILD DIABETIC } \\
(6-8 \%)\end{array}$} & \multicolumn{2}{|c|}{$\begin{array}{c}\text { DIABETIC } \\
(>8 \%)\end{array}$} \\
\hline & \multicolumn{2}{|c|}{$\mathrm{HbA1c}$} & \multicolumn{2}{|c|}{$\mathrm{HbA1c}$} & \multicolumn{2}{|c|}{$\mathrm{HbA1c}$} \\
\hline & $r$ & $\mathrm{P}$ & r & $\mathrm{P}$ & $r$ & $P$ \\
\hline $\begin{array}{l}\text { DPP-IV } \\
\text { (Fasting) }\end{array}$ & 0.5505 & 0.064 & 0.821 & 0.001 & 0.694 & 0.026 \\
\hline $\begin{array}{l}\text { DPP-IV } \\
\text { (Postprandial) }\end{array}$ & 0.2127 & 0.507 & 0.732 & 0.005 & 0.305 & 0.021 \\
\hline
\end{tabular}

$r$ - Pearson's correlation coefficient.

${ }^{*} \mathrm{P}<0.05$ is considered as statistically significant.

\section{DISCUSSION}

The present data reveals that serum DPP-IV activity has a direct correlation with the degree of hyperglycaemia in type 2 diabetes patients. Elevated levels of DPP-IV, leading to reductions in active GLP-1 that stimulate early postprandial insulin secretion, could theoretically induce an elevation of $\mathrm{HbA} 1 \mathrm{c}$ in type 2 diabetes patients. Furthermore, variations in DPP-IV are correlated with variations in $\mathrm{HbA} 1 \mathrm{c}$, meaning that impairment of metabolic control is associated with increased plasma enzyme activity. In fact, although the elevation of enzyme activity in type 2 diabetic patients with poor metabolic control could be due partly to interference from hypoglycaemic treatment (Mannucci E et al. 2001). DPP-IV levels were reported to be reduced in a small sample of elderly patients with type 2 diabetes (Meneilly GS et al. 2000). No significant difference in circulating enzyme activity was detected between type 2 diabetic patients and 
matched healthy controls and intravenous infusions of GIP and GLP-1 in moderate type 2 diabetes patients and matched control subjects it was found that the insulinotropic effect of GIP was almost lost in patients, whereas the insulin response to GLP-1 was similar to control (Vilsboll T et al. 2001). The present study data reveals that circulating serum DPP-IV activity in fasting conditions higher in diabetic subjects than normal subjects. The most probable reasons for this increase of DPP-IV may be due to uncontrolled hyperglycemia or due to enhanced activity of CD26 T cell response, which contribute to rise in circulating DPP-IV may be an inflammatory response of uncontrolled diabetic status or DPP-IV itself may increase glucagon activity, which favours hyperglycemia is not well understood. Any how, high levels of fasting serum DPP-IV activity may taken as decreased incretin response.DPP-IV mRNA expression and enzyme activity have been reported to be stimulated by hyperglycaemia in human endothelial cells in vitro Some of these studies were performed on samples of patients with a mild degree of hyperglycaemia showing that the impairment of the GLP-1 response to meals is an early event in the natural history of diabetes (Pala L et al. 2003). No comparative studies regarding fasting and post pranidial DPP-IV response in normal subjects are available in literature. It is interesting to note in our study that in normal subjects postprandial serum DPP-IV levels (after 2hours of meal) are always increased. The ratio of DPP-IV (fasting/post prandial) is in normal subjects is 0.85 $(<1)$.The cause for postprandial DPP-IV rise in normal subjects is not clear. However, it may be due to high secretion of GLP-1(incretin response) and immediate degradation or cleavage of the same to DPP-IV.

In diabetic subjects, interestingly post pranidial spike of DPP-IV is not seen in any case. It may be due to lack of secretion of GLP-1(incretin response) to food. The ratio of DPP-IV (fasting/post pranidial) is always greater than one ( $>1)$. We have not estimated directly GLP-1 in these patients. But indirectly GLP-1 secretion as incretin response is studied by DPP-IV estimation post pranidially. More secretion of GLP-1 is followed by more activity of DPP-IV as cleavage product of GLP-1 is seen. In diabetic subjects, with metformin treatment for more than three years showing $\mathrm{HbA1C}$ value greater than 8 or also having the ratio of DPP-IV (fasting / post pranidial) is greater than $1(>1)$. Metformin stimulates secretion of GLP-1. But in these patients, failure of postprandial DPP-IV is taken as parameter of drug resistance.

\section{CONCLUSION}

In conclusion, the present study indicates that responses of fasting and post pranidial DPP-IV levels to food intake may be taken as indirect evidence of incretin secretion. High levels fasting DPP-IV are correlated with high levels of HbA1c. It is an alternative parameter of uncontrolled diabetes. Postprandial rise of DPP-IV which is seen in normal subjects is absent in diabetic group. It is very interesting point. It may be taken as an index of indirect incretin gut response failure. Any how, large studies are invited for further confirmation.

\section{REFERENCES}

Bunn H. F. (1981) Glycated hemoglobin. Diabetes. 30: 613-615.

Christiansen MP, Hellerstein MK. (1998). Effects of metformin on hepatic glucose metabolism. Curr Opin Endocrinol Diabetes. 5: 252-255.

Drucker DJ, Philippe J, Mojsov S, Chick WI, Habener JF. (1987). Glucagon like peptide-I stimulates insulin gene expression and increases cyclic AMP levels in a rat islet cell line. Proc. Natl. Acad. Sci. USA 84: 3434-3438.

Durinx C, Neels H, Van der Auwera JC, Naelaerts K, Scharpe S, De Meester I. (2001). Reference values for plasma dipeptidylpeptidase IV activity and their association with other laboratory parameters. Clin Chem Lab Med. 39:155-158.

Holz GG, Leech CA, Habener JF. (1995). Activation of a cAMP-regulated Ca2+- signaling pathway in pancreatic b-cells by the insulinotropic hormone glucagon-like peptide-1. J Biol Chem. 270: 17749-17757.

Kashima Y, Miki T, Shibasaki T. (2001). Critical role of cAMP-GEFI/Rim2 complex in incretinpotentiated insulin secretion. J Biol Chem. 276: 46046-46053. 
Lambeir A-M, Durinx C, Scharpe S, De Meester I. (2003). Dipeptidyl-peptidase IV from bench to bedside: an update on structural properties, functions and clinical aspects of the enzyme DPP IV. Crit Rev Clin Lab Sci. 40: 209-294.

Light PE, Manning Fox JE, Riedel MJ, Wheeler MB. (2002). Glucagon like peptide-1 inhibits pancreatic ATP sensitive potassium channels via a protein kinase A- and ADP-dependent mechanism. Mol Endocrinol. 16: 2135-2144.

Low SH, Wong SH, Tang BL, Subramaniam N, Hong W. (1991). Apical cell surface expression of rat dipeptidyl peptidase IV in transfected Madin-Darby canine kidney cells. J Biol. 266:13391-13396.

Mannucci E, Ognibene A, Cremasco F. (2001). Effects of metformin on glucagon-like peptide-1 (GLP-1) and leptin levels in obese non-diabetic subjects. Diabetes Care. 24: 489-494.

Meneilly GS, Demuth HU, Mcintosh CH, Pederson RA. (2000). Effect of ageing and diabetes on glucose-dependent insulinotropic polypeptide and dipeptidyl peptidase IV responses to oral glucose. Diabet Med. 17:346-350.

Orskov C, Rabenhoj L, Wettergren A, Kofod H, Holst J.J. (1994). Tissue and plasma concentrations of amidated and glycine-extended glucagon-like peptide-1 in humans. Diabetes. 43: 535-539.

Pala L, Mannucci E, Pezzatini A. (2003). Dipeptidyl peptidase-IV expression and activity in human glomerular endothelial cells. Biochem Biophys Res Commun. 310: 28-31.

Trivelli LIA.(1971). Characterization of glucated hemoglobins. New Eng J Med. 284:353-356.

Vanhoof G, De Meester I, van Dande M, Scharpe S, Yaron A. (1992). Distribution of prolinespecific aminopeptidases in human tissues and body fluids. Eur $\mathrm{J}$ Clin Chem Clin Biochem. 30: 333-38.

Vilsboll T, Krarup T, Deacon CF, Madsbad S, Holst JJ. (2001). Reduced postprandial concentration of intact biologically active glucagon-like peptide-1 in type 2 diabetic patients. Diabetes. 50: 609-613.

Wang Y, Egan IM, Raygada M, Nadiv O, Roth J, Montroserafizadeh C. (1995). Glucagon-like peptide-1 affects gene transcription and messenger ribonucleic acid stability of components of the insulin secretory system in RIN 1046- 38 cells. Endocrinology. 136(11): 4910-4917.

Weyer C, Bogardus C, Mott DM, Pratley RE. (1999). The natural history of insulin secretory dysfunction and insulin resistance in the pathogenesis of type 2 diabetes mellitus. J Clin Invest. 104: 787-794.

Willms B, Werner J, Holst JJ, Orskov C, Creutzfeldt W, Nauck MA. (1996). Gastric emptying, glucose responses and insulin secretion after a liquid test meal: effects of exogenous glucagon-like peptide-1 (GLP-1)-(7-36) amide in type 2 (non-insulin dependent) diabetic patients. J. Clin. Endocrinol. Metab. 81: 327-332. 